\title{
Comparative Evaluation of Necessity of Antibiotic Administration Following Dental Extraction among Population of Age Group 30-60 Years - Triple Blinded Randomized Controlled Trial
}

Sasidharan Sivakumar ${ }^{1}$, Umesh K², Muthu Karuppaiah R³, Sangeeta Chavan'4, Palanivel Pandian R ${ }^{5}$, Prem Kumar P6

1, 2, 3, 4, 5, 6 Department of Public Health Dentistry, Best Dental Science College, Madurai, Tamil Nadu, India.

\section{ABSTRACT}

\section{BACKGROUND}

The use of antibiotics as prophylactic prescriptions remains a controversy in dentistry. The current study was done to evaluate the necessity of antibiotic administration following dental extraction among population of $30-60$ year old age groups.

\section{METHODS}

This is a triple blinded trial with trial registry number CTRI / 2019 / 12 / 022342 in which the 60 study participants were randomized and allocated in a ratio of $1: 1: 1$ to three groups A (amoxicillin $500 \mathrm{mg}$ t.d.s), B (clindamycin $150 \mathrm{mg}$ t.d.s as a mouthrinse), C (no antibiotic) by lot method. The study proceeded after ethical committee approval and informed consent from the participants. Medically compromised patients, patients in menstruation period, lactation and pregnancy period, test drug hypersensitive patients, tooth with abscess or cyst were excluded and patients of $30-60$ years old reporting with the complaint to Best Dental Science College, Madurai, were included in the study. The tooth was extracted, and evaluated on $3^{\text {rd }}, 7^{\text {th }}$ and $14^{\text {th }}$ day post-operatively.

\section{RESULTS}

The non healing parameters were observed in percentages of 9.7, 6.2 and 6.2 in group A, B and C group during the $14^{\text {th }}$ day clinical evaluation. The presence of non-healing parameters was insignificant between three groups.

\section{CONCLUSIONS}

Prophylactic antibiotics following dental extraction is unnecessary until the patient is at a state of high risk of infection. Thereby, as a dentist we could combat a step towards a developing major public health problem, "Antibiotic Resistance".

\section{KEY WORDS}

Drug Resistance, Tooth Extraction, Drug Utilization, Antibiotic Awareness, Prophylaxis
Corresponding Author:

Dr. Sasidharan Sivakumar,

Department of Public Health Dentistry,

Best Dental Science College,

Madurai, Tamil Nadu, India.

E-mail: sdmhoralcare@gmail.com

DOI: $10.14260 /$ jemds/2021/524

How to Cite This Article:

Sivakumar S, Umesh K, Karuppaiah RM, et al. Comparative evaluation of necessity of antibiotic administration following dental extraction among population of age group 30 - 60 years - triple blinded randomized controlled trial. J Evolution Med Dent Sci 2021;10(32):2554-2558, DOI: 10.14260/jemds/2021/524

Submission 25-11-2020,

Peer Review 06-06-2021,

Acceptance 12-06-2021,

Published 09-08-2021.

Copyright (C) 2021 Sasidharan Sivakumar et al. This is an open access article distributed under Creative Commons Attribution License [Attribution 4.0 International (CC BY 4.0)] 


\section{BACKGROUND}

Antibiotics usually in clinical practice are used to treat bacterial infections. Sometimes, though, dentists or physicians suggest taking antibiotics before treatment to decrease the chance of infection. This antibiotic prophylaxis is not right for everyone and like any medicine, antibiotics should only be used when the potential benefits outweigh the risks of taking them. ${ }^{1}$ For example, consider that infections after dental treatment are not common and that, in some people, antibiotics can have side effects like developing anti-microbial resistance, stomach upset, diarrheoa and allergic reactions. ${ }^{2}$ Unwise prescription of antibiotics by the dentists precipitates the initiation of antibiotic resistance. ${ }^{3}$ The National Center for Disease Control and Prevention estimate that approximately one-third of all outpatient antibiotic prescriptions are unnecessary. ${ }^{4}$ Anti-microbial resistance (AMR) threatens to sweep us to the pre-antibiotic era and this information ought to be a loud wake up call for the entire health care specialities. Studies reveal that many oral microbes such as Streptococcus spp., Prevotella spp., Fusobacteria spp., Haemophilus spp., Veillonella spp., Porphyromonas gingivalis, Aggregatibacter actinomycetemcomitans, and Actinomyces have attained resistance to multitudinal antibiotics. ${ }^{5,6}$ Systemic antibiotic therapy is widely used for prophylaxis in major head and neck surgery and also following minor surgical procedures like extractions, but the efficacy of topical oral antibiotic therapy has not been fully investigated. The routes of drug administration always plays an important role in successful treatment outcome based on their efficiency and side effects particular to those routes of administration. The most commonly used antibiotic in dental practice, penicillins in general, were found to be the most commonly prescribed antibiotics by dentists, the most popular one being amoxicillin, ${ }^{7}$ metronidazole, ${ }^{8,9}$ and amoxicillin and clavulanate. ${ }^{10}$ Clindamycin, an antimicrobial agent that has been in use worldwide for more than 3 decades, has been consistently effective in the treatment of infections involving a wide spectrum of facultative and strictly anaerobic bacteria. ${ }^{11,12}$ From a dental perspective, it would appear that the incidence of $\mathrm{C}$ difficile infection with clindamycin is no greater than that with amoxicillin or amoxicillin/clavulanate, two antimicrobial agents frequently used in the management of acute dental infection and anaphylaxis with clindamycin is also extremely rare.

\section{Objectives}

So the present study was done to evaluate the necessity of antibiotic prophylaxis following dental extraction and also the effectiveness of topical versus systemic administration of antibiotics among population of $30-60$ year old age groups.

\section{METHODS}

A prospective triple blinded randomized controlled trial with the registry number of CTRI / 2019 / 12 / 022342 was carried out on 60 patients with mean age of males $(45 \pm 12)$ and females with mean age $(40 \pm 10)$ with 95 tooth extractions based on the results of pilot study with $5 \%$ significance level and $95 \%$ confidence interval. The institutional review board ethical clearance was approved before the start of the study. The study follows ICMR's ethical guidelines for biomedical and health research on human participants (2017).

The study group consisted of patients, who reported to the Department of Public Health Dentistry, Best Dental Science College, Madurai from December 2019 to March 2020 who were indicated for extraction. Informed consent was obtained before the start of the study after explaining the need and methodology of study explicitly.

Patients who were medically compromised, female patients who were pregnant or lactating and those women during menstruation period (disturbed fibrinolytic activity), and participants who are known hypersensitives to the test drugs used in this study, and tooth with abscess and cyst and patients taking antibiotics on pre operative 5 days for any reason were all excluded, while patients aged 30 to 60 years old, gender non-specific population who were willing to participate in this study were included for the study.

The relevant pre-operative information was recorded for each patient in the data sheet including age and gender of the patient, indications for extraction (the diagnosis was based on both clinical and radiographic examinations), and tooth/teeth to be removed. The study was carried under strict aseptic precautions. Local anesthetic of $2 \%$ lignocaine hydrochloride with $1: 80,000$ epinephrine, was administered as per the requirement. The tooth was extracted, and the socket was inspected and debrided clearly. Haemostasis was achieved. After extractions, all the patients were given standard post operative instructions.

The trial subjects were randomized and allocated in ratio of $1: 1: 1$ to three groups A (amoxicillin $500 \mathrm{mg}$ t.d.s), B (clindamycin $150 \mathrm{mg}$ t.d.s as a mouthrinse), C (no antibiotic) by lot method with blindfolded lottery method with group names. After extraction, randomization is done by the nonoperating person and medications were prescribed as per the group they were allocated blinding the patient as well the clinical operator. In case for group A, the patients were prescribed with $500 \mathrm{mg}$ of tablet amoxicillin thrice daily after meals post extraction for 3 days. For group B, the clindamycin capsule of $150 \mathrm{mg}$ was prescribed and patients were instructed to dispense the contents of the capsule in a $50 \mathrm{ml}$ of water and use as a mouthrinse post-operatively after 24 hours, and the instruction was given for usage as without rigorously using the mouthrinse even for 2 days after that post-operative 24 hours. For group C, the post-operative antibiotics were not given. All the groups were prescribed with the non-steroidal anti-inflammatory drug tablet ibuprofen $400 \mathrm{mg}$ along with the $\mathrm{H} 2$ receptor blockers tablet ranitidine $150 \mathrm{mg}$ b.d before food. The study flow was depicted with consort flow diagram Figure 1.

The clinical evaluation was done post-operatively on follow-up period during $3^{\text {rd }}$, $7^{\text {th }}$ and $14^{\text {th }}$ day post-operatively Figure 2. An alveolus healing assessment form was completed for each patient, and this included the patient's biodata, day of presentation for alveolus healing assessment in which it was assessed based on the following criteria: Alveolar osteitis: Persistent or increased post-operative in and around the extraction site accompanied by a partially or totally disintegrated blood clot. Diagnosis is confirmed when extremely sensitive bare bone is encountered. Acutely inflamed alveolus: A painful alveolus with profoundly 
inflamed soft tissue but without exudates. Acutely infected alveolus - A painful alveolus with suppuration, erythema and edema with or without systemic fever. Normal healing alveolus - The post extraction socket with normal granulation tissue with or without pain. The pain on the follow up days was assessed using numeric pain rating scale with the score from 0 to 10 .

\section{Statistical Analysis}

The data were statistically analysed with Fisher Freeman Halton significance test using SPSS (Statistical Package for the Social Sciences) version 24.0 software, IBM Corporation.

\section{RESULTS}

In this study, 95 extracted sockets were evaluated for the need of prescribing prophylactic antibiotics after routine dental extraction procedure under local anesthesia. Post-operatively, during follow-up, the lost to follow up data was pictorially represented through intention to treat analysis and were replaced by expectation maximization technique Figure 3 . The variation in wound healing parameters during follow-up periods was graphically represented Figure 4, 5, 6 and the evaluation of wound healing properties revealed that the difference in healing parameter was statistically not significant among all three groups with $P$ value of $0.308,0.751$, 0.793 for within group comparison in a particular evaluation day data Table 1.

\begin{tabular}{|c|c|c|c|c|c|c|}
\hline \multirow{2}{*}{ Groups } & \multicolumn{2}{|c|}{ Day 3 N (\%) } & \multicolumn{2}{|c|}{ Day 7 N (\%) } & \multicolumn{2}{|c|}{ Day 14 N (\%) } \\
\hline & No & Yes & No & Yes & No & Yes \\
\hline A (Amoxicillin) & $22(71)$ & $9(29)$ & $24(77.4)$ & 7 (22.6) & $\begin{array}{r}28 \\
(90.3)\end{array}$ & $3(9.7)$ \\
\hline $\begin{array}{c}\text { B } \\
\text { (Clindamycin) }\end{array}$ & $18(56.2)$ & $\begin{array}{c}14 \\
(43.8)\end{array}$ & $27(84.4)$ & 5 (15.6) & 30 (93.8) & $2(6.2)$ \\
\hline $\begin{array}{c}\mathrm{C} \text { (No } \\
\text { antibiotic) }\end{array}$ & $17(53.1)$ & $\begin{array}{c}15 \\
(46.9)\end{array}$ & 27 (84.4) & 5 (15.6) & 30 (93.8) & $2(6.2)$ \\
\hline Total & $57(60)$ & $38(40)$ & 78 (82.1) & $\begin{array}{c}17 \\
(17.9)\end{array}$ & $88(92.6)$ & $7(7.4)$ \\
\hline P Value* & 0.3 & & 0.7 & & 0.79 & \\
\hline Table 1. Varic & on in $W$ & ound 1 & ling Parc & ameter & ween the & Groups \\
\hline
\end{tabular}

wound healing characterstics among different groups of medication usage.

\begin{tabular}{|c|c|c|c|c|c|c|c|}
\hline \multirow{2}{*}{ Groups } & \multicolumn{2}{|c|}{$\begin{array}{c}\text { Day } 3 \text { Pain Score } \\
\text { N (\%) }\end{array}$} & \multicolumn{3}{|c|}{ Day 7 Pain Score N (\%) } & \multicolumn{2}{|c|}{$\begin{array}{l}\text { Day } 14 \text { Pain } \\
\text { Score N (\%) }\end{array}$} \\
\hline & Mild & Moderate & $\begin{array}{c}\text { No } \\
\text { Pain }\end{array}$ & Mild I & Moderate & eNo Pain & Mild \\
\hline Amoxicillin & $22(71)$ & $9(29)$ & $5(16.1)$ & $\begin{array}{c}24 \\
(77.4)\end{array}$ & $2(6.5)$ & $24(77.4)$ & 7 (22.6) \\
\hline Clindamycin & $24(75)$ & $8(25)$ & $\begin{array}{c}10 \\
(31.2)\end{array}$ & $\begin{array}{c}22 \\
(68.8)\end{array}$ & $0(0)$ & $26(1.4)$ & $6(18.8)$ \\
\hline No antibiotic & $26(81.2)$ & $6(18.8)$ & 7 (1.9) & $\begin{array}{c}25 \\
(78.1)\end{array}$ & $0(0)$ & $28(87.5)$ & $4(2.5)$ \\
\hline Total & $72(75.8)$ & $23(24.2)$ & $\begin{array}{c}22 \\
(23.2)\end{array}$ & $\begin{array}{c}71 \\
(74.7)\end{array}$ & $2(2.1)$ & $78(82.2)$ & $17(17.9)$ \\
\hline P Value* & & .631 & & 0.290 & & 0.5 & 586 \\
\hline \multicolumn{8}{|c|}{ Table 2. Variation in Pain Score between the Groups } \\
\hline
\end{tabular}

The pain score evaluation based on numerical pain rating scale among different antibiotic groups within the same day comparison infers that participant pain score of no pain, mild and moderate has been categorized among the study participants input.
The Fisher - Freeman - Halton significance test is used and $P$ value $0.631,0.290,0.586$ for within group comparison of pain in a particular evaluation day was used. Data was not significant which denotes that the pain being an evaluation criteria is not much influenced by the antibiotic prescription Table 2.

\section{DISCUSSION}

The study results were evident that antibiotic prophylaxis is not necessary in all clinical situations during minor surgical procedure like extraction. The individual tooth extractions are taken into consideration rather than the patients for evaluating the outcome to avoid the difference in physiological influence over healing parameters in each individual. Professional articles and editorials have substantiated the consequences of misuse of antibiotics and advocated their use in a wiser way in both medicine and dentistry. If at all antibiotic prescription is required for a percentage of population who were minimally susceptible for infection, topical route could be the choice rather than systemic administration as our study results depicts equal outcome for all three groups. Thereby we can prevent many complications and drawbacks associated with the systemic administration of antibiotics.

Antibiotics have brought unquestionable benefits to modern society. However, excessive, injudicious use confers a chance for opportunistic pathogens to become resistant along with inherent side effects causing infections. In recent reports, emergence of novel multidrug resistant bacterial pathogens from India and other South Asian countries is of a serious concern for consideration. ${ }^{13}$ The prophylaxis is not always indicated when there is an absence of serious risk of infection, because of either the features or sterile quality in the operation or the local or general health conditions of the patient. Tooth extraction being considered to be a minor surgical procedure in healthy patients, which may not require prophylaxis. ${ }^{14}$ Another aspect of over-prescribing antibiotics is prescription based on non-clinical factors. Patient's expectation of an antibiotic prescription (placebo effect) as unscientific reasons for antibiotic prescription, dentists practicing in the Eastern Mediterranean region have shown a higher tendency to prescribe on a patient's demand or socially.7,15 In the present study, which agrees with Cheung et al. alveolar osteitis mostly caused severe pain, whereas the acutely infected alveolus was complicated mostly by moderate pain, and the acutely inflamed alveolus caused moderate or mild pain. Normal uncomplicated socket healing was, however, associated with mild or moderate pain, up to the third day after the extraction in $9.6 \%$ of cases, while $2.4 \%$ of patients had mild pain throughout the seven day postoperative review. ${ }^{16}$

When prescribing antibiotics, dentists should always prefer to use the shortest effective course of a narrow spectrum antibiotic. Study by Suda. J alarmed that antibiotics prescribed by dentists as a preemptive effort against infection are unnecessary $81 \%$ of the time. ${ }^{17}$ And also the quality of dental prescriptions could be improved by increasing the awareness of the recommended guidelines among all dental practitioners. 
In favour of our study a recent review by Kelli Stein, ${ }^{18}$ suggested the dilemmatic need in even therapeutic antibiotics in regular clinical situations, as there is insufficient evidence supporting the use of antibiotics to treat periapical abscess, irreversible pulpitis and symptomatic apical periodontitis, which are treated effectively through drainage by means of pulpectomy, incision, or local debridement, they should not be overprescribed.

An exception to this would be if the patient seeks care with evidence of systemic involvement, as well as a gross, rapid, and diffuse spread of infection. Moreover, antibiotic therapy is not indicated even for treating dry socket because it is not an infection. Alternatively, the treatment includes local site irrigation with saline or chlorhexidine, a dressing material to control the pain, analgesics, and the maintenance of proper oral hygiene is necessary. Dentists should consider antibiotics only when there is a persistent, severe symptom. Also studies in high-income and low-and middle-income (LMIC) countries have shown that it is often doctor's perception of patient demand rather than actual patient requirement that is associated with antibiotic overprescription. ${ }^{19}$ Targeted education of practitioners about the utility of antibiotics in this specific situation may be of great help in reducing antibiotic use. The limitation of the present study is that larger sample size is necessary to increase the strength of this inference.

\section{Clinical Significance}

The antibiotic resistance emerging a major global threat for the society needs to be concerned seriously and from dentistry the need for antibiotics if not necessarily required can be limited based on the clinical situations whenever possible.

\section{CONCLUSIONS}

The present study concludes that post-extraction prophylactic antibiotics should be prescribed only in necessity and also topical could be preferred rather than systemic administration to avoid the drawbacks associated with the systemic administration. In addition to the proper dosing regimens and professionally responsible prescribing practices, the general public needs to be educated about the importance of restricting the use of antibiotics to only cases of severe infection. Patients have become accustomed to being given an antibiotic for a range of medical complaints. Unfortunately, patients presenting at dental surgeries also routinely expect an antibiotic for the treatment of 'toothache'. ${ }^{20}$ Dental patients not only pressurize their dentist to get an antibiotic prescription, they also self-medicate. Selfmedication with antibiotics was found to be alarmingly high in some developing countries. In conclusion, prescribing practices of dentists can be improved by increasing awareness among dental practitioners of the recommended guidelines. ${ }^{21-23}$

Data sharing statement provided by the authors is available with the full text of this article at jemds.com.

Financial or other competing interests: None.

Disclosure forms provided by the authors are available with the full text of this article at jemds.com.

\section{REFERENCES}

[1] Dar-Odeh NS, Abu-Hammad OA, Al-Omiri MK, et al. Antibiotic prescribing practices by dentists: a review. Ther Clin Risk Manag 2010;6:301-6.

[2] Mark AM. What is antibiotic prophylaxis? J Am Dent Assoc 2016;147(6):526.

[3] Dajani AS, Bisno AL, Chung KJ, et al. Prevention of bacterial endocarditis: recommendations by the American Heart Association. J Endod 1991;17:169-73.

[4] Swift JQ, Gulden WS. Antibiotic therapy--managing odontogenic infections. Dent Clin North Am 2002;46(4):623-33.

[5] Hamilton WL, Wenlock R. Antimicrobial resistance: a major threat to public health. Cambridge Med J 2016;3:5.

[6] Barrett R, Kuzawa CW, Mcdade T, et al. Emerging and reemerging infectious diseases: the third epidemiologic transition. Annual Review of Anthropology 1998;27:24771.

[7] Al-Haroni M, Skaug N. Knowledge of prescribing antimicrobials among yemeni general dentists. Acta Odontol Scand 2006;64(5):274-80.

[8] Palmer NOA, Martin MV, Pealing R, et al. Paediatric antibiotic prescribing by general dental practitioners in England. Int J Paediatr Dent 2001;11(4):242-8.

[9] Palmer NO, Martin MV, Pealing R, et al. An analysis of antibiotic prescriptions from general dental practitioners in England. J Antimicrob Chemother 2000;46(6):1033-5.

[10] Roda RP, Bagan JV, Bielsa JMS, et al. Antibiotic use in dental practice. A review. Med Oral Patol Oral Cir Bucal 2007;12(3):186-92.

[11] Wilson WR, Cockerill FR $3^{\text {rd }}$ Tetracyclines, chloramphenicol, erythromycin and clindamycin. Mayo Clin Proc 1987;62(10):906-15.

[12] Brook I, Lewis MAO, Sándor GKB, et al. Clindamycin in dentistry: more than just effective prophylaxis for endocarditis? Oral Surg Oral Med Oral Pathol Oral Radiol Endodontol 2005;100(5):550-8.

[13] Thakolkaran N, Shetty AV, D'Souza NDR, et al. Antibiotic prescribing knowledge, attitudes and practice among physicians in teaching hospitals in South India. J Family Med Prim Care 2017;6(3):526-32.

[14] Salmeron-Escobar JI, De Velasco ADAM. Antibiotic prophylaxis in oral and maxillofacial surgery. Med Oral Patol Oral Cir Bucal 2006;11(3):292-6.

[15] Salako NO, Rotimi VO, Adib SM, et al. Pattern of antibiotic prescription in the management of oral diseases among dentists in Kuwait. J Dent 2004;32(7):503-9.

[16] Cheung LK, Chow LK, Tsang MH, et al. An evaluation of complications following dental extractions using either sterile or clean gloves. Int J Oral Maxillofac Surg 2001;30(6):550-4.

[17] Suda KJ, Calip GS, Zhou J, et al. Assessment of the appropriateness of antibiotic prescriptions for infection prophylaxis before dental procedures 2011 to 2015 . JAMA Netw Open 2019;2(5):e193909.

[18] Stein K, Farmer J, Singhal S, et al. The use and misuse of antibiotics in dentistry: a scoping review. J Am Dent Assoc 2018;149(10):869-84.e5.

[19] Wigton RS, Darr CA, Corbett KK, et al. How do community practitioners decide whether to prescribe antibiotics for acute respiratory tract infections? J Gen Intern Med 
2008;23(10):1615-20.

[20] Lewis MAO. Why we must reduce dental prescription of antibiotics: European Union antibiotic awareness day. Br Dent J 2008;205(10):537-8.

[21] Awad AI, Eltayeb IB. Self-medication practices with antibiotics and antimalarials among Sudanese undergraduate university students. Ann Pharmacother 2007;41(7):1249-55.
[22] Al-Azzam SI, Al-Husein BA, Alzoubi F, et al. Selfmedication with antibiotics in Jordanian population. Int J Occup Med Environ Health 2007;20(4):373-80.

[23] Yousef AMM, Al-Bakri AG, Bustanji Y, et al. Selfmedication patterns in Amman, Jordan. Pharm World Sci 2008;30(1):24-30. 